\title{
The Planning and Preparation of the Technical Information Pilot and Its Cumulative Index
}

Dr. Taube is chief, Science and Technology Project, Library of Congress.

S PART of its work for the Office of A Naval Research, the Science and Technology Project of the Library of Congress abstracts research reports submitted by government contractors, and issues these abstracts on catalog cards and in a loose-leaf bulletin. Neither the bulletin nor the cards is available for general distribution, but the method used in their preparation may readily be adapted and used by other scientific information agencies.

In planning the preparation of the Technical Information Pilot, and its cumulative index (hereafter referred to as TIP and TIP Index), the Science and Technology Project of the Library of Congress was able to build upon the successful experience of two other Library of Congress publications, namely, the Cumulative Catalog of Library of Congress Printed Cards, and the Monthly Checklist of State Publications. An account of the preparation of the Cumulative Catalog is contained in a paper by C. D. Gull of the staff of the Science and Technology Project, which was read at the fall meeting of the American Chemical Society, Sept. 16, 1947. Loan copies of this paper are available from the project and will be until the paper is published. Except for administrative reports in the files of the Library of Congress, no account exists of the method of preparation used for the Monthly Checklist of State Publications.

For these publications, copy for pages is produced by mounting printed or typed cards. The Cumulative Catalog makes use of a $3^{\prime \prime} \times 5^{\prime \prime}$ Library of Congress catalog card from which the leading has been removed in printing so that the finished pages will not have the white spaces which characterize ordinary Library of Congress printed cards. On the other hand, the Monthly Checklist is prepared from 4" × 6" typed cards. Experiments with various typed surfaces have shown that an attractive two-column page can be prepared by typing in a $4^{\prime \prime} \times 5^{\prime \prime}$ area, leaving one inch of the card for taping on the right margin. IBM proportional spacing typewriters are used and provide a text surface of uniform blackness which is ideal for reproduction by photo-offset.

The preparation of TIP and its index posed several problems not faced in the preparation of either of the publications referred to above. The Cumulative Catalog could be planned on the basis of an existing supply of $3^{\prime \prime} \times 5^{\prime \prime}$ printed catalog cards. The Monthly Checklist, being noncumulative, needed only one typed card for each monthly issue and the library unit preparing the Monthly Checklist had no need for $3^{\prime \prime} \times 5^{\prime \prime}$ cards. On the other hand, the Science and Technology Project needed multiple cards in order to prepare the cumu- 
lative index and a dictionary catalog of the material in its possession; and it needed subject headings on the cards in order to be able to file the cards properly and to cumulate them satisfactorily for the quarterly indexes. Hence, it was necessary to design a basic typed card which could be used: ( I) for the production of an abstract bulletin, (2) for the production of cumulative indexes, and (3) for the production of $3^{\prime \prime} \times 5^{\prime \prime}$ catalog cards to be used within the project and for distribution to other libraries which might desire to integrate catalog cards produced by the Science and Technology Project with their own catalogs. It was further necessary to design

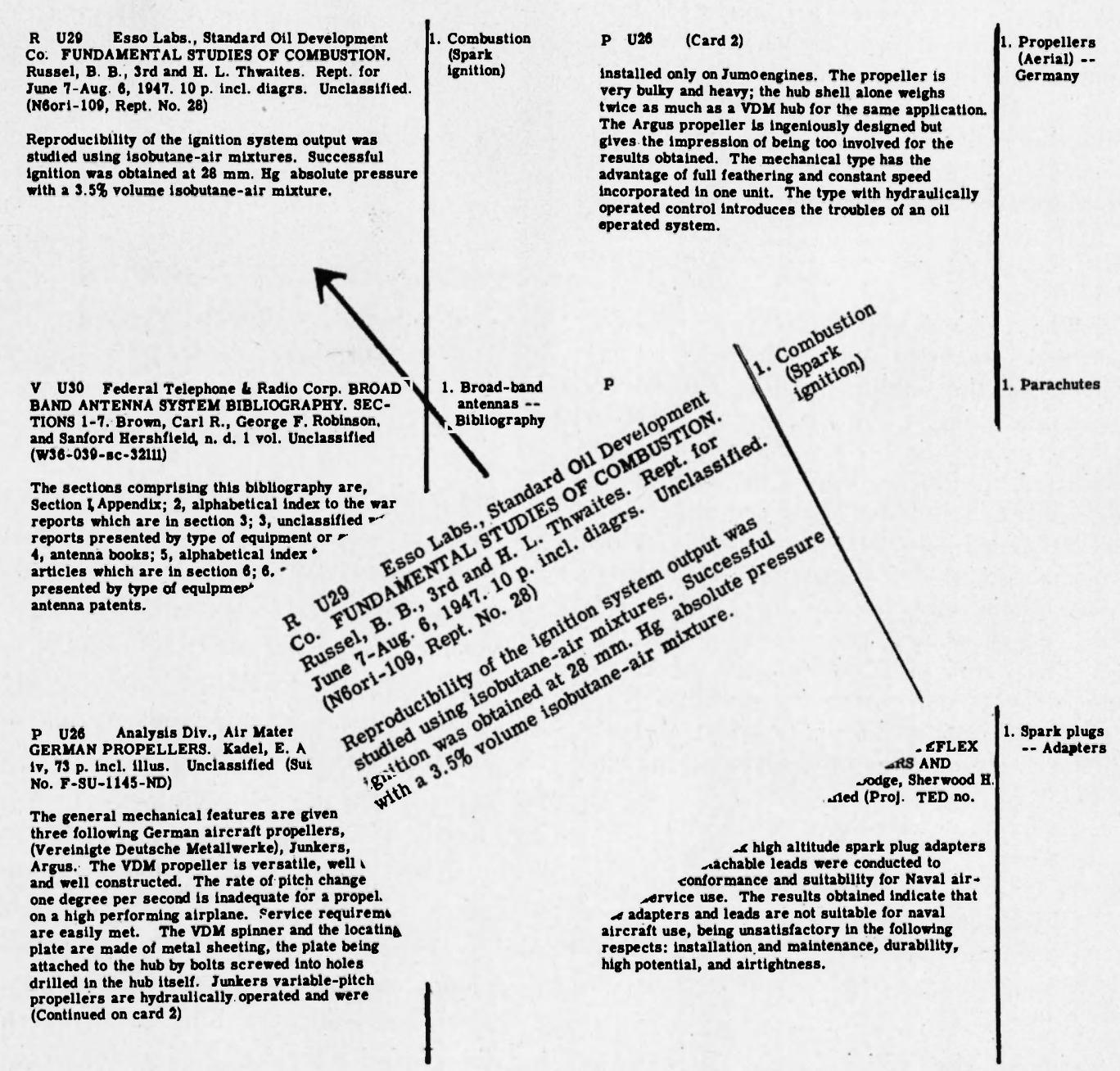

Figure $I$ the cards so that the subject headings would appear on the individual cards but not on the pages.

In designing this card, we began with the demonstrated adequacy of a $4^{\prime \prime} \times 5^{\prime \prime}$ typed surface for producing an attractive and legible two-column page. Experiments indicated that this $4^{\prime \prime} \times 5^{\prime \prime}$ area was adequate in most instances for a full catalog entry and a complete abstract, but if subject headings are placea in this space, the space available for the abstract is cut seriously enough to require a large percentage of twocard entries. The answer to this problem was discovered by recognizing that the area of the card which was overlapped and taped 
in producing the page could be utilized for the subject headings in preparing the card. Thus, the basic card measuring 4 " deep and 62" wide was designed. Of the width, $\frac{3}{8}$ " was reserved for the margin, $4 \frac{5}{8}$ " for the catalog entry and abstract, and $I_{3}^{2}$ " for subject headings and other tracings.

Perhaps the clearest picture of the various problems and their solutions can be given by an actual account of the steps necessary to produce both the $3^{\prime \prime} \times 5^{\prime \prime}$ cards and the finished page:

I. Entry, abstract, and subject headings are typed on a $4^{\prime \prime} \times 63^{2 \prime \prime}$ card (shown as the overlaid card in Fig. I).

2. Six $4^{\prime \prime} \times 63^{2 \prime}$ cards are mounted on a cardboard without overlapping, and reduced photographically 25 per cent.

3. A multilith plate is prepared from the reduced negative and the plate is then run off on card stock to produce six $3^{\prime \prime} \times 5^{\prime \prime}$ cards per sheet (the sheet is shown as background in Fig. I).

4. The sheets are cut and the individual 3 " $\times 5$ " cards are ready for distribution.

5. The original typed cards are removed from their mounting and remounted. In this remounting the subject headings are overlapped like shingles and the cards are closed up so that all unnecessary white spaces are eliminated. After the cards are mounted in this manner, a heading, date, and page number are added. In preparing this page, the adjustable lining device invented by the Government Printing Office and described in Mr. Gull's paper is used (illustrated in Fig. 2).

6. The cards mounted in page form are reduced by 35 per cent and a multilith plate is prepared from which pages of the abstract bulletin are run off (a finished page is shown in Fig. 3).

7. Every three months a cumulative index to the abstract bulletin is prepared by mounting the $3^{\prime \prime} \times 5^{\prime \prime}$ cards and overlapping both the subject headings and abstracts. Every entry is given under all the subject headings which appeared on the original card (as shown in Fig. 4).

Although the initial purpose in placing the subject headings at the side was to

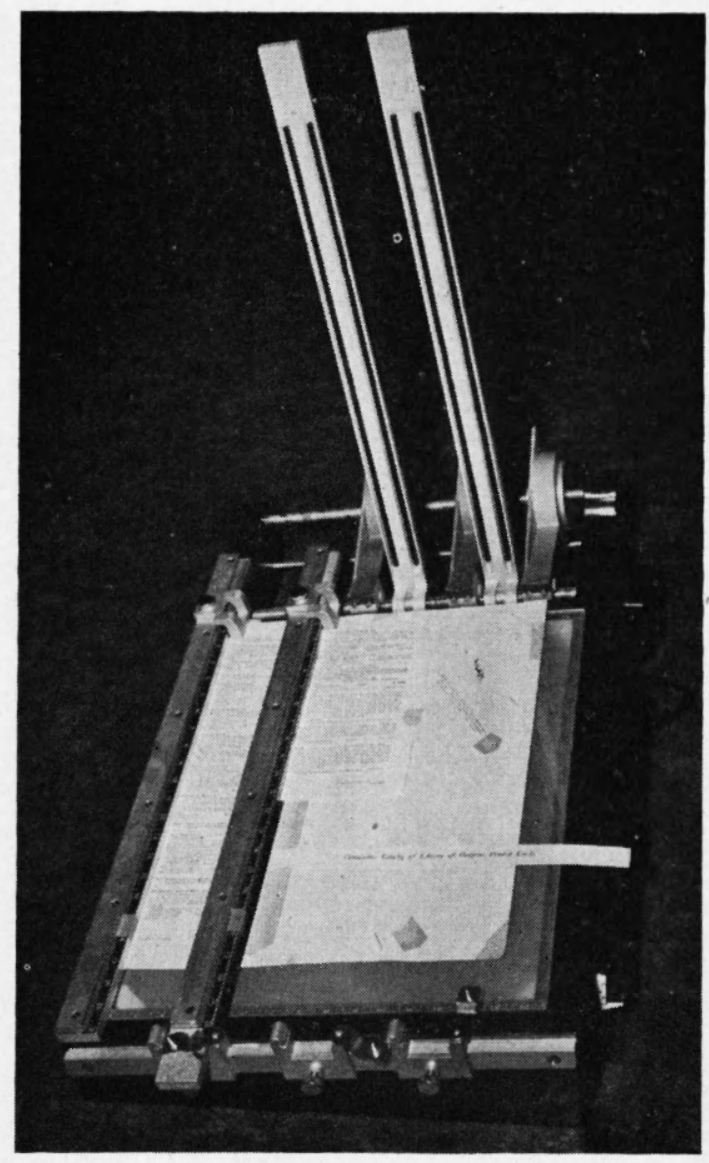

Figure 2

solve a make-up problem, the card, when designed, exhibited certain advantages over the ordinary catalog card which places the subject headings at the bottom of the card. In the first place, the subject headings on the card designed for TIP stand out boldly and prominently. Second, the position on the side of the card makes it possible to file the cards under the various subject headings by checking them or circling the numbers, thus eliminating an extra typing operation. There is sufficient room for adding tracings for secondary entries, such as personal authors, editors, etc.

Finally, something should be said concerning the symbol which appears at the beginning of each entry prepared for TIP, e.g., 
one or several balloons; use of eight brake parachutes, use of single large parachute suspended above gondola by all balloons, use of eight standard parachutes suspended by two balloons each, and use of eight standard parachutes each syspended by ten balloons. The last method is suggested as offering the greatest margin of safety because all balloons are attached to the apex of the parachutes.

R U28 Aeronautical Engine Lab., Naval Air Experimental Station, Phila. TESTS OF. TITEFLEX HIGH ALTITUDE SPARK PLUG ADAPTERS AND UNIMOLD DETACHABLE LEADS. Dodge, Sherwood $H$. Aug. 7, 1947, 9p. illus. Unclassified (Proj. TED no. NAM-04531)

Tests of the Titeflex high altitude spark plug adapters and unimold detachable leads were conducted to determine conformance and suitability for Naval aircraft service use. The results obtained indicate that the adapters and leads are not suitable for naval aircraft use, being unsatisfactory in the following respects: installation and maintenance, durability, high potential, and airtightness.

R U29 Esso Labs., Standard Oil Development Co. FUNDAMENTAL STUDIES OF COMBUSTION. Russel, B. B., 3rd and H. L. Thwaites. Rept. for June 7-Aug. 6, 1947. $10 \mathrm{p}$. incl. diagrs. Unclassified. (N6ori-109, Rept. No. 28)

Reproducibility of the ignition system output was studied using isobutane-air mixtures. Successful ignition was obtained at $28 \mathrm{~mm}$. $\mathrm{Hg}$ absolute pressure with a $3.5 \%$ volume isobutane-air mixture.

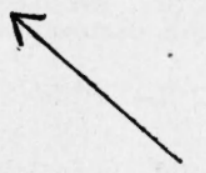

V U30 Federal Telephone \& Radio Corp. BROAD BAND ANTENNA SYSTEM BIBLIOGRAPHY. SECTIONS 1-7. Brown, Carl R., George F. Robinson, and Sanford Hershfield, n. d. 1 vol. Unclassified (W36-039-sc-321II)

The sections comprising this bibliography are, Section I Appendix; 2, alphabetical index to the war reports which are in section $3 ; 3$, unclassified war reports presented by type of equipment or subject; 4 , antenna books; 5 , alphabetical index to the antenna articles which are in section $6 ; 6$, antenna articles presented by type of equipment or subject; 7 , antenna patents.

ZZ U31 Engineering Div., Air Materiel Command. ORGANIZATION AND DIRECTORY CHARTS. Sept. 15, 1947, 1 vol. Unclassified.

ZZ U32 Naval Research Lab. LIBRARY BULLETIN NO. 291. June $13,1947,1$ vol. Unclassified.

Abstracts of periodicals.

ZZ U33 Technical Intelligence Branch, Engineer. Research \& Development Labs., Fort Belvoir. DOCU. MENT ACCESSION LIST VOL. 1, NO. 13. Nov. 14, 1947,25 p. Unclassified.
R U29. The first letter, $R$, indicates the major subject classification of the report, such as Geophysics, Power, or Communication. These over-all categories are identical with the classification of research projects now being developed for the Office of Naval Research by the Science and Technology Project. The remaining letter and number, U29, serve to establish the identity of the report uniquely. 


\section{TECFNICAL DNFORMATION PILOT CUMULATIVE INDEX}

\section{ACRYLIC RESINS}

E U11 Aeronautical Materials 1 ab., Naval Air Experimontal Station, Phila. ACRYLIC PLAsTIC SHEET-METHODS FOR MAINTEN/ANCE AND REPAIR-SPECIFICATION AN-C-154, COMPOUND, POLISHING (FOR ACRYLIC PLASTIC) - PROPOBED AMEND. -1 TO ANA SPEC. Cassola, C. A. and Leonard J. Mielsel. Jan. 28, 1947, 6 p. dlagrs. tables Unclassified (Rept. No. AML-NAM 25623)

\section{ALUMINUM ALLOYS}

E 08 Aeronautical Materials Lab., Naval Air Experimental Station, Phila. INVESTIGATION OF METALLURGICAL AND MECHANICAL PROPERTIES OF Rsos alUMmUM ALlOY. Dougherty, C. M. June 20, 1947, 1 vol. (variously paged) lllus. tables. Unclassified ( Rept. No. AML NAM 25287, Part IV)

\section{ANEROID CHAMBERS}

- 09 Battelle Memorial Inst. IMPROV SMENT IN CAPBULES FOR BENBTTVE ALTIMETERS. Progress Rept. No. 14, June 6-July 6, 1947. 400448 p. incl. illus. Unclassifled (W36-039-8C32009)

\section{BROAD-BAND ANTENNAS -- BIBLIOGRAPHY}

$\checkmark$ USO Federal Telephone 4 Radio Corp. BROAD BAND ANTENNA SYSTEM BIBLIOGRAPHY. SECTIONS 1-7. Brown, Carl R., George F. Robinson, and Sanford Hershfield, n. d. 1 vol. Unclassified (w36-030-sc-32111)

\section{CATHODE RAY TUBES}

G 017 Cornell 0 . RADAR DISPLAY RESEARCH. Relnnagel, R. E., M. G. Foster, and X. D. Swartzel. Monthly Progress Rept. No. 10. June 27, 1947, 3 p. Unclassified (W28-099-ac-214, Rept. No. 434 P-10)

\section{COMBUSTION (SPARK IGNITION)}

R U29 Esso Labs., Standard Oll Development Co. FUNDAMENTAL STUDIES OF COMBUSTION. Russel, B. B., 3rd and H. L. Thwaites. Rept. for June 7-Aug. 6, 1947. $10 \mathrm{p}$. Incl. diagrs. Unclassifled. (N6ori-109, Rept. No. 28)

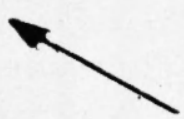

\section{COMPRESSIBLE FLOW}

F 013 National Advisory Committee for Aeronautics. A THEORY OF UNSTAGGERED AIRFOIL CABCADES IN COMPRESSIBLE FLOW. Bpurr, Robert A. and H. Julian Allen. Research memo. Sept. 2, 1047, 42 p. incl. diagrs. Unclassified (Rept. RMNo. ATE20)

\section{COPPER ALLOYS}

- 09 Battelle Memorial inst. IMPROVEMENT IN CAPBULEB FOR BENBTTVE ALTMMTERB. Progress Rept. No. 14, June 6-July 6, 1947. 400440 p. incl. lllus. Unclassifled (W36-039-8c32000)

\section{DEUTERONS}

C 03 Argonne National Lab. THE MAGNETIC MOMENTS OF THE NEUTRON AND THE DEUTERON. Arnold, W. R. and A. Roberts. Nor. 25, 1946, 17 p. incl. diagrs. Unclassified (Document MDDC 440)

To be abstracted by the Office of Technical Services of the Department of Commerce in its Bibliography of Bcientific and Industrial Reports.

\section{ELECTRON TUBE SOCKETS}

a 016 Cinch Mfg. Corp. DEVELOPMENT OF AN . TRMETICALLY 8EALED ELECTRON TUBE 8OCKET. Del Camp, s. June 2, 1947, 14 p. incl. diagrs. Unclassified (W33-038-ac-15280, Rept. No. 3)

\section{INSULATION (ELECTRICAL)}

E 012 Johns Hopkdns U. THE EFFECT OF MOISTURE AND FUNGUS ON THE ELECTRICAL AND MECHANICAL PROPERTIES OF PLASTIC INSULATNGG MATERIALS. Mar. - Apr. 1947, 2 p. Unclassifled (W28-009-ac-70)

Periodic status report.

MASS SPECTROSCOPES

C 06 Atomic Energy Commission. MA88 8PECTROBCOPE FOR RAPID ANALY8B IN LOW MAss RANGE. 8ir1, William. Jan. 18, 1947 (declassiGed Mar. 7, 1947), 3 p. Unclassified W7405-Eng-48; OEM-CMR-198 (Document no. MDDC-789)

To be abstract by the Office of Technical Borvices of the Department of Commerce in its Blbllography a 8 clentific and Industrial Reports. 